\title{
PENGGUNAAN BAHASA NONVERBAL DALAM \\ UPACARA ADAT PERNIKAHAN GAYA YOGYAKARTA: \\ KAJIAN SIMBOLIK ETNOPRAGMATIK
}

The Use of Nonverbal Language in Yogyakarta Style Traditional Wedding Ceremonies: A Symbolic Study of Ethnopragmatics

\section{Pranowo $^{a}$ dan Winci Firdaus ${ }^{\mathrm{b}}$}

${ }^{a}$ Universitas Sanata Dharma Yogyakarta.

${ }^{b}$ Badan Pengembangan dan Pembinaan Bahasa

prof.pranowo2@gmail.com,wincifirdaus@yahoo.com

Naskah Diterima Tanggal 4 September 2019_Direvisi Akhir Tanggal 24 Mei 2019_Disetujui Tanggal 7 April 2020 doi: https://doi.org/10.26499/rnh/v9i1.2321

\begin{abstract}
Abstrak
Penelitian ini merupakan penelitian reflektif interpretatif dengan teori kajian simbolik etnopragmatik. Sumber data penelitian diambil dari dokumen dua orang juru rias dari Yogyakata, yaitu rias pengantin Lisandra dan rias penantin $\mathrm{Hj}$. Rochayati (nama disamarkan). Data penelitian berupa dokumen foto perkawinan adat Jawa gaya Yogyakarta. Teknik pengumpulan data berupa observasi dokumentasi foto untuk mendapatkan data berupa urutan upacara perkawinan yang menggunakan bahasa verbal dan bahasa nonverbal dari persiapan sampai dengan akhir. Teknik analisis data dilakukan secara reflektif interpretatif. Langkah konkret analisis data adalah (a) mengidentifikasi dokumen, (b) mengklasifikasi urut-urutan acara perkawinan, dan (c) menginterpretasi tiap tahapan upacara. Tujuan penelitiannya adalah (1) mendeskripsikan wujud bahasa nonverbal dalam upacara adat perkawinan, dan (2) mendeskripsikan makna simbolik etnopragmatik bahasa nonverbal dalam upacara adat perkawinan. Temuan hasil penelitian adalah bahwa (a) wujud acara adat perkawinan gaya Yogyakarta terdapat 15 tahapan, mulai dari paningsetan sampai dengan resepsi, dan (b) makna simbolik etnopragmatik pada umumnya berupa doa permohonan agar apa yang diinginkan dapat terwujud.
\end{abstract}

Kata kunci: adat perkawinan, makna simbolik, etnopragmatik.

\begin{abstract}
This research is an interpretive reflective research with ethnopragmatic symbolic study theory. The source of the research data was taken from the documents of two makeup artists from Yogyakata, namely the makeup dresser Lisandra and the makeup dresser Hj. Rochayati. The research data are in the form of Javanese traditional wedding document of Yogyakarta style. The data collection technique is in the form of observation of photo documentation to obtain data in the form of a marriage ceremony sequence that uses verbal and nonverbal language from preparation to the end. The data analysis technique is interpretive reflective. The concrete steps of data analysis are (a) identifying documents, $(b)$ classifying the sequences of marriages, and (c) interpreting each stage of the ceremony. The objectives of the research are (1) to describe the form of nonverbal language in traditional marriage ceremonies, and (2) to describe the non-verbal symbolic meaning of non-verbal language in marriage ceremonies. The findings of the research are that (a) the form of Yogyakarta-style traditional wedding events there are 15 stages, ranging from paningsetan to reception, and (b) ethnopragmatic symbolic meaning in general in the form of prayer requests so that what is desired can be realized.
\end{abstract}

Keywords: marriage customs, symbolic meaning, ethnopragmatics.

How to Cite: Pranowo dan Winci Firdaus. (2020). Penggunaan Bahasa Nonverbal dalam Upacara Adat Pernikahan Gaya Yogyakarta: Kajian Simbolik Etnopragmatik. Ranah: Jurnal Kajian Bahasa, 9(1), 35-55. doi: https:// doi.org/10.26499/rnh/v9i1.2321 


\section{PENDAHULUAN}

Adat perkawinan merupakan salah satu peristiwa tutur yang terjadi di hampir seluruh lingkungan budaya masyarakat. Memang, setiap budaya masyarakat memiliki perspektif yang berbeda-beda mengenai adat perkawinan. Di Jawa, sumber utama adat perkawinan berasal dari keraton Surakarta dan Yogyakarta. Masyarakat biasa kemudian ingin meniru adat keraton ketika menikahkan anak-anak mereka. Namun, tata upacara adat yang terjadi dilaksanakan di keraton tidak semua dapat dilaksanakan oleh masyarakat biasa karena berbagai pertimbangan. Hal ini tergantung pada (a) rasa percaya diri pihak keluarga terhadap status sosial dalam masyarakat, (b) kemampuan dana yang disiapkan oleh keluarga, (c) pengetahuan yang dimiliki oleh pengelola upacara (EO) adat perkawinan, (d) kepercayaan diri keluarga terhadap acara adat perkawinan, dan (e) hasil diskusi antara pihak keluarga dengan EO. Hal itulah yang akhirnya menjadi keputusan bersama pihak keluarga (Aji, 2015).

Atas dasar berbagai petimbangan tersebut, upacara adat perkawinan di masyarakat menjadi variatif. Variasi tata cara adat masyarakat umum yang terjadi di daerah Yogyakarta biasanya berkiblat ke keraton Kasultanan Yogyakarta, sedangkan masyarakat di daerah Surakarta berkiblat ke keraton Mangkunegaran dan Kasunanan. Namun, khusus Pura Pakualaman di Yogyakarta, adat perkawinannya cenderung berkiblat ke Surakarta karena asal-usul tradisi adat perkawinan Pura Pakualaman di bawa dari adat keraton Surakarta (Studi, Bahasa, \& Mada, 2016).

Peristiwa perkawinan adat gaya Yogyakarta, biasanya didominasi tata cara upacara menggunakan bahasa nonverbal, yaitu pihak keluarga dan mempelai perempuan maupun laki-laki hanya menjalankan tata urutan yang dipandu oleh juru rias dan pembawa acara. Dengan demikian, fokus pemakaian bahasa verbal ada di pihak pembawa acara dan juru rias. Sementara itu, pihak keluarga mempelai sebagian besar berbahasa nonverbal. Namun demikian, semua wujud dan makna pragmatik diperuntukkan pihak mempelai berdua dan kedua orang tua dan besan. Terlepas dari berbagai kiblat yang dianut oleh masyarakat, penelitian ini difokuskan pada adat perkawinan masyarakat umum Yogyakarta yang cenderung berkiblat pada gaya Keraton Yogyakarta.

Penelitian terdahulu pernah dilakukan oleh (Nuning, 2016) mengenai makna simbolik upacara "panggih pada Upacara Perkawinan Adat Jawa Tengah Prespektif Performance studies". Upacara panggih merupakan acara ritual yang diharapkan dapat menggambarkan kehidupan bahagia kedua mempelai di kemudian hari. Hal ini memperlihatkan hubungan 
panggih pada upacara perkawinan adat Jawa Tengah dengan konteks sosial yang disusun dan dibentuk oleh masyarakat agraris dan memunculkan tanda-tanda yang berkaitan erat dengan pola hidup agraris.

Penelitian lain yang dilakukan (Ambarwati \& Anindika, 2018) berjudul "Pernikahan Adat Jawa sebagai Salah Satu Kekuatan Budaya Indonesia” menunjukkan bahwa pernikahan adat Jawa sebagai salah satu kekuatan budaya Indonesia yang memiliki cirri khas yang dapat membedakan budaya Jawa dengan budaya lainnya yang ada di Indonesia. Ciri khas yang dimaksud adalah sederetan acara yang khas dalam budaya Jawa, seperti (1) siraman: membersihkan diri menjelang acara besar, (2) midodareni: simbol malam yang baik untuk bersilaturahmi, (3) injak telur: dimaknai harapan dan lambing kesetiaan, (4) sikepansindur: tali kasih yang erat dan tak terpisahkan, dsb. Serangkaian acara tersebut merupakan warisan leluhur yang dapat menjadi kekuatan budaya Indonesia.

Hal lain adalah penelitian Herina Yuwati berjudul "Makna Simbolis yang Terdapat Pada Riasan Wajah dan Aksesoris pada Pengantin Gaya Yogya Paes Ageng” (Yuwati, 2018). Tujuan penelitian ini adalah mendeskripsikan bentuk riasan dan asesori pengantin gaya Yogya paes ageng, mendeskripsikan asal usul riasan wajah dan asesori pengantin gaya Yogya paes ageng, dan makna simbolis pada riasan wajah dan asesosi pengantin paes ageng gaya Yogya.

Dari beberapa penelitian di atas ternyata belum ada yang mendeskripsikan bahasa nonverbal dalam rangkaian acara pernikahan upacara adat pernikahan gaya Yogyakarta yang dikaji secara simbolik etnopragmatik. Oleh karena itu, penelitian ini menggunakan pendekatan simbolik etnopragmatik. Teori pragmatik difokuskan pada (a) pengertian studi pragmatik dan (b) konteks pragmatik, sedangkan teori etnografi difokuskan pada peristiwa budaya dalam perkawinan adat gaya Yogyakarta. Sementara itu, kajian simbolik dimanfaatkan untuk menginterpretasi berbagai makna yang terkandung dalam serangkaian upacara. Dengan demikian, interpretasi kebanyakan dilakukan secara reflektif interpretatif atas dasar kemampuan peneliti untuk memaknai setiap simbol upacara yang digunakan dalam perkawinan.

Atas dasar uraian tersebut, permasalahan utama penelitian ini "Bagaimanakah penggunan bahasa nonverbal dalam upacara adat pernikahan gaya Yogyakarta?’. Submasalahnya adalah (1) wujud bahasa nonverbal apa sajakah yang digunakan dalam upacara adat perkawinan gaya Yogyakarta, dan (2) makna simbolik etnopragmatik apa sajakah yang terdapat dalam penggunan bahasa nonverbal pada upacara adat perkawinan 
Jawa gaya Yogyakarta? Tujuan penelitiannya adalah (1) ingin mendeskripsikan wujud bahasa nonverbal yang digunakan dalam upacara adat perkawinan Jawa gaya Yogyakarta, dan (2) ingin mendeskripsikan makna simbolik etnopragmatik penggunaan bahasa nonverbal dalam upacara adat perkawinan Jawa gaya Yogyakarta.

\section{LANDASAN TEORI}

Penelitian ini ingin mengungkap berbagai makna pragmatik yang diwujudkan secara simbolis berupa barang atau benda dalam upacara adat pernikahan gaya Yogyakarta menggunakan pendekatan etno pragmatik. Pendekatan kajian etnografi adalah pendekatan penelitian yang diterapkan untuk mengungkap makna sosio-kultural dengan cara mempelajari keseharian pola hidup dan interaksi kelompok sosio-kultural dalam konteks tertentu. Ketika melakukan penelitian, seorang etnografer berupaya menyatu dalam kehidupan kultural suatu kelompok masyarakat yang diteliti (observer participant) untuk mengenal pola perilaku, sistem keyakinan, bahasa, dan nilai kultural yang diyakini dan dianut oleh masyarakat. Salah satu objek kajian etnografi adalah masalah bahasa sebagai salah satu unsur kebudayaan (Koentjaraningrat, 2000; Hartati, 2011).

Di sisi lain, pendekatan kajian pragmatik merupakan pendekatan penggunaan bahasa atas dasar konteks. Konteks yang dimaksud adalah segala aspek yang berada di luar tuturan tetapi ikut menentukan makna pragmatik (Brown \& Yule, 2013). Oleh karena itu, penelitian bahasa nonverbal pada dasarnya adalah penelitian bahasa di luar kata-kata (Lapakko, 2016).

Konteks berdasarkan sudut pandang ahli satu dengan yang lain berbeda-beda. Widdowson (1989) mendefinisikan konteks sebagai "... aspek-aspek dari keadaan penggunaan bahasa aktual yang dianggap relevan dengan makna". Dengan kata lain, konteks adalah konstruksi skematik dalam pencapaian makna pragmatik yang ada kecocokan kode unsur linguistik dengan elemen skematiknya. Cook (2003) yang mempelajari hubungan wacana dengan sastra, menyatakan bahwa konteks hanyalah sebuah bentuk pengetahuan dunia (knowledge of the world). Maksudnya, segala pengetahuan dunia yang dimiliki si penutur dapat berfungsi sebagai konteks ketika bertutur. Ahli lain, mengidentifikasi konteks menjadi dua, yaitu konteks statis dan konteks dinamis (Hu, 2014).

Dey (2017) menyatakan bahwa konteks adalah segala informasi yang dapat digunakan untuk menentukan situasi suatu entitas. Entitas dapat berupa orang, tempat, atau objek yang dianggap relevan dengan interaksi antar pengguna. Dash (2008) membuat klasifikasi konteks menjadi 4 (empat) macam, yaitu (a) konteks Lokal (konteks yang mengacu pada lingkungan 
terdekatnya), (b) konteks sentensial (konteks yang mengacu pada kata kunci dalam kalimat yang terjadi), (c) konteks topik (konteks yang mengacu pada topik diskusi dan berfokus pada konten dari sepotong teks), dan (d) konteks global (yang dimaksud bahwa kata bukanlah entitas yang terisolasi tetapi kata-kata selalu saling terkait dengan kata-kata lain dan juga dengan realitas ekstralinguistik (Verschueren, 2008).

Secara umum, sejumlah besar informasi dari konteks global tersedia di dunia luar, yang memasok isyarat vital, seperti tempat, waktu, situasi, interpretasi, pragmatik, wacana, demografi, geografi, masyarakat, budaya, etnologi, dan berbagai hal lainnya (Allan, 2001). Karena konteks pemahaman global antara bahasa dan kenyataan, kita sering menyebutnya "siapa yang mengatakan, apa yang dikatakan, kepada siapa dikatakan, kapan dikatakan, di mana dikatakan, mengapa dikatakan, dan bagaimana mengatakannya". Dengan demikian, konteks global menjadi sumber informasi berharga makna disambiguaitas kata-kata, dan itu membantu kita mengerti apakah kata kunci yang memiliki variasi makna. Berdasarkan uraian mengenai konteks di atas dapat diidentifikasi pengertian konteks sebagai berikut.

1. Konteks adalah "... aspek-aspek dari keadaan penggunaan bahasa aktual yang dianggap relevan dengan makna" (Widowson, 1989).

2. Konteks adalah bentuk pengetahuan dunia (knowledge of the world) (Cook, 2003). Maksudnya, segala pengetahuan dunia yang dimiliki si penutur dapat berfungsi sebagai konteks ketika bertutur.

3. Konteks adalah segala informasi yang dapat digunakan untuk mengkarakterisasi situasi suatu entitas. Entitas dapat berupa orang, tempat, atau objek yang dianggap relevan dengan interaksi antara pengguna dan aplikasi, termasuk pengguna dan aplikasi itu sendiri(Ambarwati, Alda Putri Anindika, 2018).

Atas dasar identifikasi tersebut, pengertian konteks merupakan segala informasi, pengetahuan dunia berupa aspek-aspek keadaan penggunaan bahasa aktual yang relevan dengan makna untuk menandai entitas tertentu (seperti orang, tempat, objek dalam suatu tuturan). Dengan demikian, pengertian konteks dapat dijelaskaan atas dasar beberapa hal sebagai berikut.

a) Atas dasar keberadaan dalam tuturan, konteks dibedakan menjadi dua, yaitu konteks statis dan konteks dinamis (Hu, 2014).

b) Atas dasar jangkauan konteks, konteks dapat dibedakan menjadi konteks sempit dan konteks luas (Cook, 2003).

c) Atas dasar wujud dalam tuturan, konteks dibedakan menjadi dua yaitu: (a) konteks lokal, dan (b) konteks topical (Miller \& Leacock, 2000).

d) Atas dasar lingkungannya, konteks diklasifikasikan menjadi 4 (empat), yaitu (a) konteks Lokal, (b) konteks sentensial, (c) kontekst topik, dan (d) konteks global (Dash, 2008).

e) Atas dasar alat interpretasi, konteks sebagai alat untuk menginterpretasi banyak makna pragmatik karena makna pragmatik tidak mungkin dipahami tanpa memahami konteks yang ada. 
Di samping itu, kajian pragmatik adalah kajian penggunaan bahasa berdasarkan konteks pemakaiannya (Brown et al., 2013). Tannenbaum (2017) mendefinisikan pragmatik adalah cabang linguistik yang mempelajari bahasa dari sudut pandang pengguna. Hua, Farah, \& Nayef. (2012: 831-848) mendefinisikan pragmatik sebagai "studi tentang pemahaman dan produksi bahasa melalui tindakan dalam konteks". Pemahaman dan produksi bahasa termasuk tindakan berbahasa dalam konteks. Makna pragmatik satuan terbesarnya adalah wacana. Kadang-kadang interpretasi makna pragmatik hanya dilakukan terhadap satu kata tetapi sudah dapat disebut sebagai wacana utuh karena koheren dengan konteksnya. Misalnya: “Diam!” (konteksnya: penutur adalah seorang guru yang sedang marah ketika siswanya ramai di kelas). Meskipun hanya terdiri atas satu kata, tuturan “diam!” adalah wacana ketika dikaitkan dengan konteks tuturannya. Dengan demikian, tuturan tersebut dapat disebut sebacai wacana (Hilmi:2019).

Atas dasar uraian tersebut, pengertian pragmatik pengertian pragmatik dapat dideskripsikan sebagai berikut.

a) Pragmatik sebagai disiplin ilmu yang mempelajari hubungan tanda dengan penafsir, dalam arti sebagai cabang ilmu bahasa yang mempelajari bahasa dari sudut pandang pengguna atas dasar konteks.

b) Pragmatik adalah kajian penggunaan bahasa berdasarkan konteks pemakaiannya (Brown et al., 2013).

c) Pragmatik adalah cabang linguistik yang mempelajari bahasa dari sudut pandang penggunaTannenbaum (2017)

d) Pragmatik sebagai "studi tentang pemahaman dan produksi bahasa melalui tindakan dalam konteks" Hua, Farah, \& Nayef. (2012). Pemahaman dan produksi bahasa termasuk tindakan berbahasa dalam konteks. Makna pragmatik satuan terbesarnya adalah wacana.

Sementara itu, interpretasi secara simbolik pemakaian bahasa nonverbal dalam acara upacara adat perkawinan gaya Yogyakarta dapat diartikan bahwa setiap perlengkapan upacara adat perkawinan mengandung makna simbolik yang bersifat filosofis (Singgih, 2017). Hampir semua perlengkapan dalam perkawinan tidak ada yang mengandung makna lugas tetapi harus selalu perlu ditafsirkan makna simbolik apa yang terdapat dalam setiap perlengkapan upacaranya.

\section{METODE PENELITIAN}

Penelitian ini merupakan penelitian deskriptif kualitatif. Sumber data penelitian adalah peristiwa upacara perkawinan adat Jawa gaya Yogyakarta yang dikelola oleh event organizer Lisandra dan $\mathrm{Hj}$. Rochayati (nama disamarkan). Data penelitian berupa tindakan bahasa noverbal yang digunakan dalam upacara adat perkawinan Jawa gaya Yogyakarta. Teknik 
pengumpulan data yang digunakan adalah (a) observasi, (b) dokumentasi berupa foto peristiwa perkawinan, dan (c) wawancara dengan nara sumber. Observasi yang dimaksud adalah mengamati beberapa acara perkawinan gaya Yogyakarta oleh Lisandra. Wawancara dengan nara sumber dilakukan dengan Kunjana Rahardi sebagai pakar pragmatik dan Sudaryanto sebagai pakar bahasa Jawa dan Linguistk. Kedua pakar tersebut, di samping untuk dimintai pendapat mengenai konsep pagmatik sekaligus sebagai validator hasil analisis pranata sosial acara perkawinan adat Jawa gaya Yogyakarta.

Teknik analisis data dilakukan secara reflektif-interpretatif (hal ini hampir belum pernah dilakukan oleh para ahli pragmatik) dengan langkah-langkah konkret adalah (a) mengidentifiksi data bahasa verbal dan nonverbal, (b) membuat klasifikasi data, (c) menginterpretasi hasil analisis data. Mengidentifikasi data yang dimaksud adalah berusaha menemukan ciri penanda khas yang berkaitan dengan wujud bahasa nonverbal, dan makna pragmatik bahasa nonverbal. Klasifikasi data dimaksudkan untuk menemukan kategorikategori bahasa nonverbal secara kronologis yang terjadi dalam upacara perkawinan adat Jawa. Selanjutnya, penelti menginterpretasi secara etnopragamtik yang terkandung dalam rangkaian upacara adat perkawinan Jawa gaya Yogyakarta.

\section{PEMBAHASAN}

Sesuai dengan rumusan masalah dalam penelitian di atas, masalah yang dijawab melalui penelitian ini meluputi (a) wujud bahasa nonverbal dalam pranata sosial pernikahan adat Jawa gaya Yogyakarta, dan (b) makna pragmatik yang terkandung dalam bahasa nonverbal perkawinan adat Jawa gaya Yogyakarta. Secara berturut-turut dibahas sebagai berikut.

\section{Wujud Bahasa Nonverbal dalam Pranata Sosial Pernikahan Adat Jawa}

Wujud bahasa nonverbal dalam pranata sosial upacara pernikahan adat Jawa gaya Yogyakarta dapat dideskrisikan secara kronologis sebagai berikut. Acara adat pernikahan gaya Yogyakarta dilakukan melalui beberapa tahap. Tahap persiapan, wujud bahasa nonverbalmeliputi (a) nontoni, lamaran, paningsetan, (b) tarup dan bleketepe, (c) siraman, (d) ngerik, (d) midodareni, ( e) jonggolan/ nyantri, (f) tantingan, (g) majemukan. Tahap inti meliputi (a) Ijab Kabul, (b) upacara panggih,(c) penyerahan tebusan berupa pisang sanggan, (d) kepyok (menyentuhkan kembar mayang ke bahu mempelai laki-laki, (e) melempar 
gantal (saling lempar sirih, (f) wijikan dan injak telur, (g) kacar-kucur, (h) sungkeman, dan (i) dhahar kembul. Tahap akhir adalah resepsi (Ambarwati \& Anindika, 2018).

Secara ringkas, butir-butir setiap tahapan dideskripsikan sebagai berikut. Tahap nontoni, lamaran, dan paningsetan. Tahap ini merupakan tahap awal ketika seseorang akan menikah. Dalam tradisi Jawa, pihak pria bersama keluarganya datang ke pihak perempuan untuk melamar dan sekaligus memberikan paningset (pasok tukon) sebagai tanda bahwa pihak keluarga pria sungguh-sungguh ingin meminang wanita yang diinginkan (Pratama, 2018). Ketika mengajukan lamaran, di samping pihak pria menyampaikan maksud secara verbal, sekaligus ada tindakan nonverbal yang dilakukan, yaitu membawa berbagai barang dan cincin utuk paningset sebagai konteks bahasa verbal. Perhatikan tuturan verbal berkut.

\begin{tabular}{|c|c|c|}
\hline Pihak pria & : & $\begin{array}{l}\text { Nuwun sewu, sowan kula kalian yoga kula bebasan "ngebun-bun enjang } \\
\text { njejawah sonten", minangka tiyang sepuh, bebasan "anak polah bapa } \\
\text { kepradhah". Menawi kepareng, kula badhe nyuwun bilih putri Bapak ingkang } \\
\text { asesilih "Genduk Agnes Yulianti" badhe kula jodokaken kalian yogya kula } \\
\text { "Damar Sasongko". Minangka tandha sarujukipun pirembagan keparenga kula } \\
\text { ngaturaken tali asih sepasang kalpika kagem adicara liru kalpika (Gambar 1: } \\
\text { Pasang cincin). }\end{array}$ \\
\hline Pihak wanita & : & $\begin{array}{l}\text { Matur nuwun awit rawuhipun Bapak saha Ibu. Minangka tiyang sepuh, kula } \\
\text { namung nyumanggakaken larenipun. Awit ing zaman sakmenika bebasan "Kebo } \\
\text { nusu gudel". Awit lare kekalih sampun sami sarujuh, minangka tiyang sepuh, kula } \\
\text { naming saget nyarujuki. }\end{array}$ \\
\hline Pihak pria & : & $\begin{array}{l}\text { Inggih matur nuwun Bapak saha Ibu. Minangka tanda rembag sami sepuh, } \\
\text { keparenga kula nyaosi tetenger kagem gendhuk Agnes, arupi kalpika. }\end{array}$ \\
\hline Konteks & : & $\begin{array}{l}\text { Tuturan lokal (Jawa) yang disampaikan menggunakan bahasa Jawa halus } \\
\text { bahkan ada kata-kata arkhais (sepertiyoga, kalpika, ngebun-ebun enjang - } \\
\text { njejawah sonten). }\end{array}$ \\
\hline
\end{tabular}

Tuturan tersebut adalah bahasa verbal "lamaran" dan pemberian paningset (pengikat kesepakatan) dari pihak laki-laki kepada pihak perempuan. Setelah ada kesepakatan, mereka menentukan waktu untuk mengadakan acara perkawinan.Tindakan nonverbal selanjutnya adalah pemasangan bleketepe. Bleketepe adalah anyaman daun kelapa yang dipasang di "tritisan" (letak air mengucur dari genting). Pemasangan bleketepe dilakukan orang tua pihak perempuan secara simbolis, pembacaan doa permohonan agar acara dapat berlangsung dengan baik (doa tidak terdengar karena diucapkan dalam hati). Dalam praktiknya, acara itu sekaligus memasang "kerun" (gapura di depan rumah untuk masuk para tamu) yang dipenuhi dengan berbagai tanaman, seperti tebu wulung, janur kuning, daun kemuning, kelapa gading, pisang raja dua tandan (Gambar 2: Kerun). Konteks: kerun adalah bagian dari acara adat Jawa tergolong bahasa nonverbal statis yang digunakan sebagai tempat masuknya tamu. 


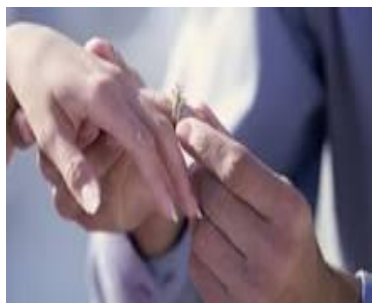

Gambar 1.

Pasang Cincin

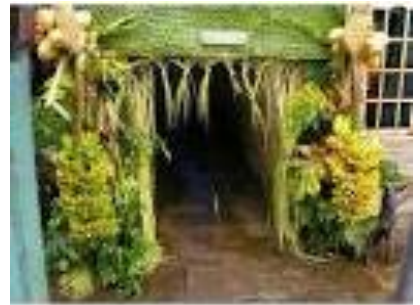

Gambar 2. Kerun/Gapura

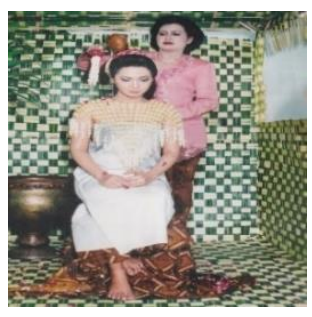

Gambar 3.

Siraman

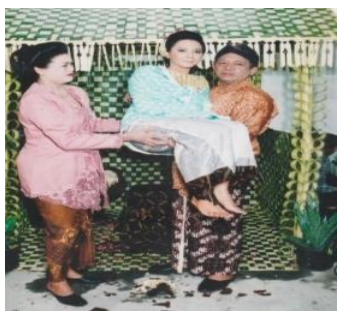

Gambar 4.

Bubak Kawah

Pada waktu yang sama dengan pemasangan bleketepe, di tempat lain dilakukan acara siraman. Siramaan diperuntukkan mempelai perempuan, sedangkan mempelai laki-laki dilaksanakan di rumah mereka sendiri. Acara siraman ini dimaksudkan untuk mensucikan diri dari berbagai kotoran, baik kororan fisik maupun kotoran hati agar ketika menghadapi acara inti ijab kabul dapat terlaksana dengan lancar (gambar 3: Siraman). Ketika siraman selesai, mempelai wanita (jika anak sulung) diadakan acara bubak kawah (Gambar 4: Bubak Kawah) yaitu sehabis siraman, mempelai wanita dibopong oleh ayahnya dan dibawa ke tempat pelaminan untuk dipaes (dikerik) (gambar 5: Paes). Acarangerikuntuk membersihkan sinom (bulu-bulu halus yang ada di pelipis) dan alis mata agar saat dipaes (dirias) dapat nampak rapi dan cantik. Pada acara ngerik ini dilakukan oleh juru rias. Konteks: acara ngerik sebagai bahasa nonverbal dinamis karena ada aktivitas verbal perias terhadap mempelai perempuan.

Tahap persiapan berikutnya adalah midodareni (harapaan agar ada bidadari dari surga yang datang untukmemberi doa atas perkawinan mereka). Acara midodareni adalah acara tirakat mempelai wanita untuk tidak tidur dari pukul 18.00-12.00. Selama waktu itu, mempelai wanita selalu berdoa agar Tuhan yang Maha Esa mengirimkan bidadari dari surga yang cantik jelita untuk memberikan kecantikan kepada mempelai wanita. Selama malam midodareni, keluarga dan sanak saudara ikut bertirakat memberi dukungan doa kepada mempelai wanita (Gambar 6: pingitan). Suasana malam midodareni pada umumnya terjadi dengan penuh sukacita, tetapi mempelai perempuan tetap berada di kamar untuk bertirakat. Konteks: bahasa nonverbal statis, mempelai wanita duduk di kamar pengantin sambil berdoa untuk memohon agar acara ijab Kabul dapat terlaksana dengan lancar.

Acara jonggolan/nyantri ini dilakukan pada saat akan midodareni. Pada saat itu, pihak keluarga mempelai laki-laki datang menyerahkan berbagai perlengkapan untuk syarat ijab kabul, sekaligus menyerahkan mempelai pria untuk dinikahkan. Mempelai pria datang bersama keluarganya untuk pasok tukon (penyerahan perlengkapan untuk ijab kabul) sekaligus majemukan. Perlengkapan pasok tukon berupa uang tunai sebagai mas kawin, 
perlengkapan alat sholat, dan pisang sanggan/pisang raja dua sisir yang sudah matang (Gambar 7: pisang sanggan). Bersamaan dengan pasok tukon sekaligus ada acara majemukan, kedatangan orang tua mempelai pria membawa berbagai kebutuhan dapur untuk membantu pihak wanita yang akan mengeluarkan biaya cukup besar untuk acara ijab kabul atau resepsi. Mereka saling bersilaturahmi dan bertirakat di malam hari. Di samping itu, disertai pula dengan berbagai perlengkapan pakaian wanita (baju, sepatu, sendal, kain, dll.) beserta oleh-oleh (buah tangan) berupa makanan untuk keluarga perempuan (Gambar 8: uba rampe oleh-oleh). Khusus pisang sanggan, (pisang dua sisir jenis pisang raja) biasanya yang diserahkan secara simbolis dari pihak pria kepada pihak wanita. Dalam acara pasok tukon, sekaligus diadakan acara "tantingan" (menanya kesanggupan terakhir pada perempuan untuk dinikahkan). Acara ini kedua orang tua mendatangi mempelai perempuan di kamar "pingitan" dan menanyakan kesediaan untuk dinikahkan dengan pria calon suaminya. Konteks: acara pasok tukon, majemukan, midodarenai, nyantri, dan tantingan adalah bahasa nonverbal dinamis karena ada aktivitas yang dilakukan oleh para keluarga dan sanak saudaranya.

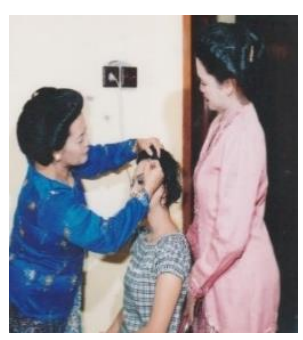

Gambar 5. Paes/Rias

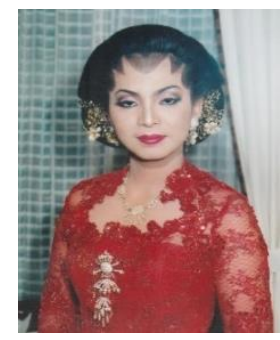

Gambar 6. Pingitan

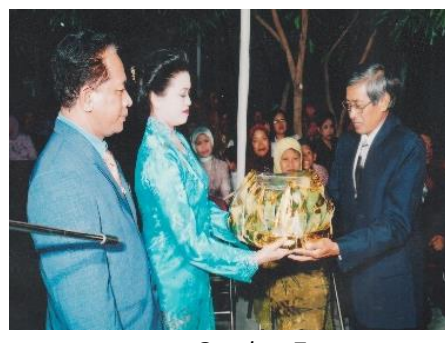

Gambar 7. Pisang Sanggan

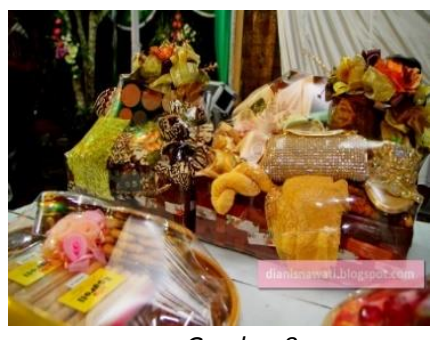

Gambar 8.

Oleh-oleh

Tahap inti adalah ijab kabul. Acara ijab kabul adalah acara resmi pernikahan. Acara ini dilakukan oleh orang tua atau wali perempuan disaksikan pegawai Kantor Urusan Agama (KUA) sebagai petugas pencatatan dalam buku nikah. Pada saat ijab kabul, bahasa nonverbal orang tua mempelai wanita berhadapan dengan mempelai pria dan saling berjabat tangan. Mempelai wanita berada di sebelah kiri mempelai pria. Biasanya didampingi petugas dari KUA untuk mencatat keabsahan ijab kabul kedua pasangan dan memberikan buku nikah kepada kedua mempelai. Orang tua mempelai perempuan dalam posisi berhadapan dengan mempelai pria dengan tangan kanan saling berjabat tangan. Pada saat itulah, orang tua pria mengucapkan kata-kata ijab kabul (Gambar 9: ijab kabul). Konteks: acara ijab kabul di samping ada bahasa nonverbal statis juga ada bahasa verbal karena orang tua mempelai wanita mengucapkan kata-kata ijab kabul ( Sari, 2017). 
Acara sudah selesai, kemudian dilanjutkan acara adat. Acara adat dimulai dengan acara panggih, yaitu mempertemukan kedua mempelai yang telah sah menjadi suami istri yang disertai beberapa rentetan acara yang lain. Hal ini dilakukan setelah acara ijab kabul. Ketika acara panggih, secara simbolis diadakan acara kepyok, yaitu menyentuhkan kembar mayang ke bahu mempelai pria. Kembar Mayang terbuat dari bahan janur yang dirangkai dengan ditancapkaan pada debog (potongan pohon pisang) sebanyak dua rangkaian didampingi dengan cengkir gading yang kulitnya dilukis dengan tokoh wayang Komajaya dan Dewi Ratih dengan doa harapan agar kedua mempelai dapat hidup rukun seperti kehidupan Komajaya dengan Dewi Ratih (Gambar10: kepyok Kembar Mayang). Meskipun demikian, wujud dan jenis kembar mayang sangat tergantung pada kelihaian pembuatnya dengan makna simbolik yang terkandung di dalamnya adalah doa-doa harapan. Konteks: acara ini merupakan acara adat Jawa menggunakan bahasa nonverbal dinamis karena ada kegiatan menyentuhkan kembar mayang ke tubuh mempelai pria (Hu, 2014).

Ketika acara pangih terjadi, mereka melakukan acara saling melempar gantal (sirih yang digulung diisi dengan tembakau, pinang, dan gambir yang diikat dengan benang lawe (benang sutra). Acara ini dipandu oleh juru rias (Gambar 11: lempar gantal). Konteksnya: acara adat dengan bahasa nonverbal dinamis karena ada aktivitas melempar gantal (sirih). Peristiwa lempar gantal dan injak telur ada pula yang dibalik.

Setelah acara injak telur, kemudian dilanjutkan acara wijikan (cuci kaki). Mempelai wanita mencuci kaki mempelai pria dengan menggunakan air yang dilengkapi dengan kembang setaman atau kembang manca warna (bunga lima warna: kantil, mawar merah, mawar putih, kenanga, dan melati) (Gambar 12: injak telur dan cuci kaki). Konteks: acara ini merupakan acara adat Jawa dengan bahasa nonverbal dinamis karena ada aktivitas nonverbal, mempelai wanita mencuci kaki mempelai pria setelah melakukan acara injak telur. Hal ini mengandung makna simbolik bagi masyarakat pemilik budaya itu (Takkaç Tulgar, 2019).

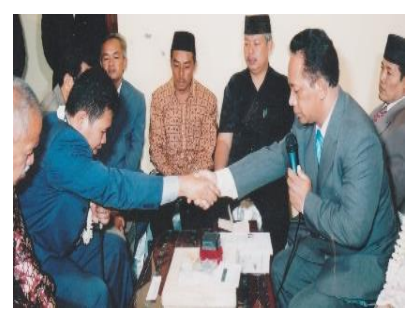

Gambar 9. ljab kabul

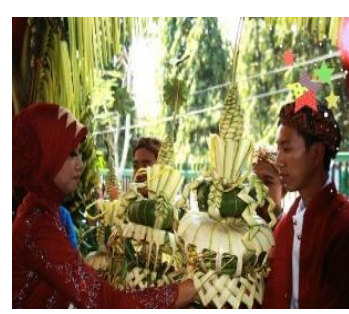

Gambar 10.

Kembar mayang

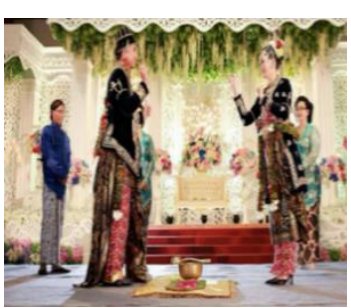

Gambar 11. Lempar gantal

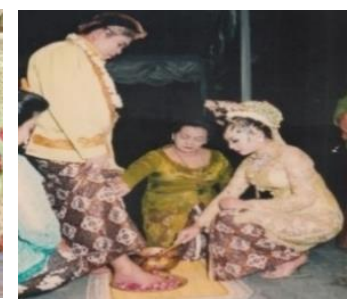

Gambar 12. Cuci kaki 
Setelah acara injak telur, kedua mempelai diarak oleh orang tua perempuan dibawa ke pelaminan. Mempelai berdua diselimuti dengan kain sindur, yaitu kain batik berwarna merah putih lebar sekitar 0,5 m dan panjang sekitar 2 meter. Kain sindur diselimutkan pada kedua mempelai dan dipegang oleh orang tua laki-laki dan diikuti ibu mempelai wanita (gambar 13: Menyelimuti kain sindur).

Setelah kedua mempelai duduk di pelaminan, mempelai pria dan wanita melakukan acara kacar-kucur yang dipandu juru rias. Acara kacar-kucur adalah simbolisasi penyerahan harta kekayaan yang dikumpulkan oleh suami agar disimpan oleh istri untuk memenuhi kebutuhan hidup keluarga (Gambar 14: kacar-kucur). Konteks: acara adat menggunakan bahasa nonverbal dinamis karena ada gerakan mengucurkan harta kekayaan suami kepada istri. Barang kacar-kucur berisi beras, biji kedelai, biji kacang-kacangan sebagai simbolisasi harta kekayaan keluarga yang diserahkan kepada istri untuk disimpan dan digunakan memenuhi kebutuhan keluarga..

Acara sungkeman dilakukan setelah acara kacar-kucur, yaitu kedua mempelai memohon doa kepada kedua orang tua mereka secara bergantian. Orang tua dalam posisi duduk, sedang kedua mempelai berposisi berjalan jongkok mendekat kedua orang tua mereka (Gambar 15: sungkeman). Inti acara ini adalah ingin memohon doa kepada orang tua agar perkawinan mereka dapat berjalan langgeng. Konteks: di samping ada gerakan bahasa nonverbal sekaligus ada tuturan bahasa verbal. Tuturan pihak mempelai kepada kedua orang tua mereka yang terucap adalah "Bapak, saya akan menjalani hidup baru dengan suami. Mohon bapak berkenan memberi doa agar kami dapat hidup rukun sampai “kaken-kaken ninen-ninen" serta menjadi keluarga yang selalu berkah, sakinah, mawadah, dan warahmah".

Dengan posisi sungkem seperti itu, orang tua menjawab “Anakku Erna, sayangi suamimu dan hiduplah selalu rukun. Jika ada masalah, kalian selesaikan berdua agar permasalahan tidak berlarut-larut. Bapak akan selalu mendoakan kalian berdua agar menjadi keluarga yanag hidup rukun selalu diberkahi Allah Swt sehingga kalian dapat hidup penuh berkah, sakinah, mawadah, dan warahmah". Berikutnya adalah acara suap-suapan (suami menyuapi istri dan istri menyuapi suami (Gambar 16: suap-suapan). Acara ini melambangkan bahwa sebagai suami istri selalu saling hidup rukun, saling membantu, dan saling bekerja sama dalam suka dan duka. 
Keseluruhan acara adat telah berakhir kemudian dilanjutkan acara resepsi. Resepsi adalah acara di luar pakem (pokok) adat perkawinan Jawa. Meskipun demikian, sudah sangat lazim jika sehabis acara adat, tuan rumah menyelenggarakan acara resepsi, yaitu acara mengundang sanak saudara, tetangga dan sahabat baik dari pihak orang tua maupun pihak mempelai berdua. Acara ini intinya adalah mohon doa restu agar kedua mempelai hidup bahagia dalam menjalani hidup berumah tangga sekaligus memberitahukan bahwa anaknya sudah menikah.

Meskipun acara ini bersifat mirunggan (mana suka), tetapi justru acara inilah yang akan menjadi citra status sosial keluarga. Semua tamu akan datang satu per satu untuk berjabat tangan dengan kedua orang tua, kedua mempelai, dan kedua besan. Setelah acara berjabat tangan dilanjutkan dengan kembul bujono (makan bersama). Ada yang cara menjamunya dengan prasmanan (mengambil sendiri makanan yang disediakan) dan ada pula yang disajikan satu per satu. Masyarakat Jawa menyebutnya "piring terbang”.

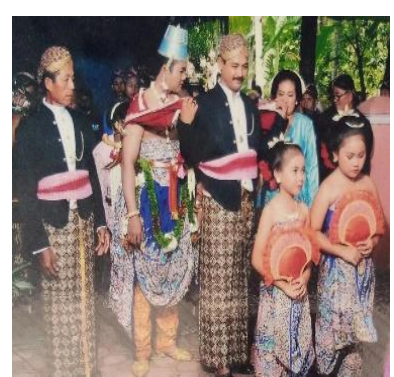

Gambar 13. Sinduran

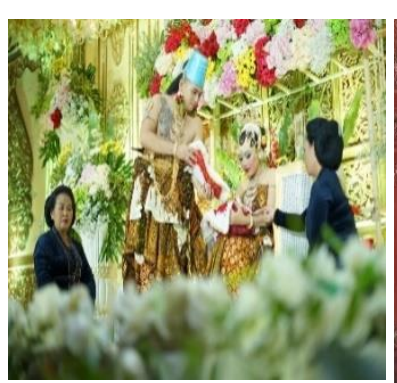

Gambar 14.

Kacar-kucur

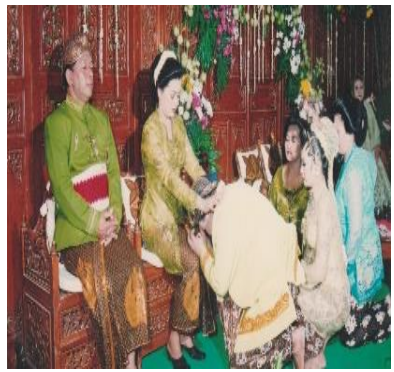

Gambar 15.

Sunakeman

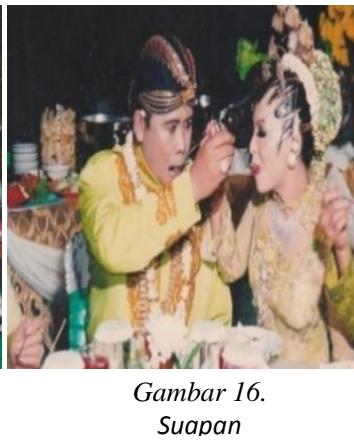

Makna pragmatik Simbolik Bahasa Nonverbal dalam Pranata Sosial Pernikahan Jawa gaya Yogyakarta

Seperti sudah dinyatakan di atas, wujud bahasa nonverbal adalah bahasa yang menggunakan selain kata-kata. Karena sebagian besar upacara perkawinan adat Jawa ditampilkan dalam wujud bahasa nonverbal berupa benda-benda yang mengandung makna simbolik, peneliti perlu memberi penafsiran makna pragmatik (maksud) penutur berdasarkan tradisi masyarakat Jawa.

Dalam praktiknya, urutan acara adat bebeda-beda, ada yang dilaksanakan dan ada yang dihilangkan. Hal inilah yang menjadi tantangan peneliti karena penafsiran yang dilakukan oleh warga masyarakat satu dengan warga masyarakat lain kadang-kadang juga berbeda. Oleh karena itu, sebagai peneliti hanya akan memberikan deskripsi penafsiran berdasarkan kesepakatan yang diyakini oleh masyarakat. Pemaknaan secara pragmatik, benda-benda 
yang dipergunakan sebagai perlengkapan upacara adat perkawainan Jawa, banyak yang tidak dapat ditemukan kaidah linguistik atau pragmatiknya. Banyak kata yang pemaknaannya "othak-athik gathuk" yang sering disebut sebagai kerata basa atau jarwa dhosok (Suwardi, 1996). Meskipun demikian, memang ada beberapa istilah Jawa yang mengandung makna simbolis filosofis. Namun, yang utama adalah makna pragmatik (maksud yang ingin diungkapkan oleh penuturnya). Oleh karena itu, makna pragmatik dalam artikel ini akan mengikuti apa yang dimaksud oleh penuturnya (Setyaningsih E., 2015). Secara bertuturturut, makna pragmatik upacara adat perkawinan Jawa dimaknai sebagai berikut.

Acara lamaran dan paningsetan merupakan acara persiapan untuk meminang mempelai wanita oleh keluarga pria untuk meminta kesedian pihak wanita agar diperkenankan untuk dijadikan pasangan hidup pihak laki-laki. Apabila pembicaraan ini sudah sepakat, pihak pria memberikan tanda bukti paningset. Paningsetan berasal dari kata dasar singset yang bermakna ikatan kesepakatan kuat antara pihak pria dan wanita bahwa keduanya akan menjalin hubungan pernikahan. Tanda bukti paningset adalah berupa sepasang cincin yang dikenakan untuk kedua mempelai. Dalam acara paningsetan, kedua keluarga sekaligus berembuk untuk menentukan kesepakatan hari pernikahan. Konteks: acara paningsetan adalah berupa konteks lokal Jawa yang dilaksanakan sebelum acara pernikahan (Verschueren, 2008). Acara paningsetan berupa pemasangan cincin kepada calon mempelai berdua bermakna pragmatik telah ada kesepakatan antara kedua mempelai dan kedua pihak orang tua.

Setelah ada kesepakatan hari pernikahan, pihak wanita membuat persiapan dengan berbagai tata cara adat. Pertama, pemasangan bleketepe. Dalam acara pemasangan bleketepe, sekaligus pemasangan tarup dan mengadakan upacara siraman. Konteks: pemasangan bleketepe dilakukan di rumah keluarga pihak wanita sebagai simbolisasi agar tidak panas karena terik matahari atau tidak terkena air ketika hujan (Setyaningsih E., 2015).

Bersamaan dengan pemasanangan bleketepe, pihak keluarga wanita dibantu sanak saudara dan tetangga melakukan pemasangan tarup, yaitu pemasangan hiasan rumah menggunakan berbagai jenis tanaman yang membentuk kerun (gapura), yang bahannya terdiri atas bambu wulung (hitam kemerah-merahan) sebagai kerangka kerun, anyaman janur (daun kelapa muda), batang tebu wulung, daun kemuning, pisang raja dua tandan, sejanjang cengkir gading. Berdasarkan kerata basa Jawa, tarup berarti ditata karep ben murup (ditata biar menyala). Arti kata murup tidak dimaksudkan menyala seperti nyala api, tetapi dalam arti kias, yaitu indah atau gumebyar (Aji, 2015; Suwardi, 1996). Dengan 
demikian, fungsi tarup adalah untuk menciptakan suasana agar tempat perkawinan menjadi indah dan terang-benderang. Setiap barang yang dipasang berdasarkan adat tradisi Jawa memiliki makna simbolik. Kerun berbentuk gapura yang dibuat dengan kerangka bambu wulung (bambu yang kulitnya berwarna hitam) untuk menempelkan anyaman janur (daun kelapa muda yang masih berwarna kuning), sebagai kerangka untuk menempelkan janur yang dianyam seperti bleketepe. Janur yang dipasang untuk membuat kerun (gapura) merupakan kerata basa Jawa, yaitu "sakjane ana nur" (sebenarnya ada cahaya). Cahaya yang dimaksudkan adalah bermakna pragmatik simboliss metaforis berupa permohonan agar dalam acara perkawinan selalu dipenuhi dengan cahaya yang selalu memberi suasana terang di hati seluruh keluarga yang sedang mengadakan acara.

Salah satu bahan untuk membuat kerun adalah batang tebu wulung (batang tebu yang berwarna ungu). Tebu wulung berasal dari kerata basa Jawa. Kata tebu di kerata dari "antebing kalbu" (kemantapan hati) dan wulung berasal dari kata gumulung (terdapat aliterasi: persamaan bunyi konsonan "ng") yang berarti berbulat hati. Dengan demikian, tebu wulung dapat dimaknai "hatinya sudah mantap dan bulat" untuk membangun mahligai rumah tangga. Makna pragmatiknya adalah bahwa kedua mempelai sudah memiliki ketetapan hati (antebing kalbu) untuk hidup sebagai suami istri.

Bahan untuk membuat kerun yang lain adalah daun kemuning dimaknai secara simbolik yang melambangkan kesucian dan keheningan (jernihnya) pikiran. Kemuning diambil suku kata terakhir yaitu“-ning”menjadi weningberarti bening atau jernih/tenang, tenteram. Makna etnopragmatik filosofis daun kemuning adalah harapan dan permohonan agar suasana hati mempelai bersama keluarganya selalu "wening" (tenang) selama acara berlangsung.

Kerun juga dilengkapi dengancengkir gading (kelapa muda jenis gading "kuning”). Makna Simbolikya cengkir gading ada beberapa macam, yaitu (a) berdasarkan kerata basa berarti "kencenging pikir" (kuatnya kemauan). Cengkirgading bentuknya bulat, berwarna kuning keemasan, (b) cengkir adalah gambaran rahim seorang wanita tempat jabang bayi. Makna simbolik etnopragmatik agar keluarga yang hidup berumah tangga diharapkan segera mendapat keturunan, (c) tafsiran lain, orang Jawa mempercayai bahwa orang yang memiliki tanaman kelapa gading akan selalu rela diminta untuk keperluan hajatan tanpa meminta biaya apapun. Karena itu, dua janjang (tangkai) kelapa gading melambangkan harapan agar pengantin bisa hidup dengan kesabaran dan kerelaan untuk berkorban terhadap sesama. 
Dengan demikian, makna etnopragmatik cengkir gading adalah memiliki sifat-sifat yang selalu sabar dan rela berkorban.

Pisang raja dua tandan yang dipotong bersama batang dan daunnya dipasang di kirikanan gapura. Makna filosofinya bahwa pisang hanya berbuah sekali dan oleh karena itu, ketika menikah diharapkan hanya sekali saja seumur hidup. Dengan demikian, makna etnopragmatiknya, sebagai suami istri diharapkan dapat menjadi pasangan abadi selama masih hidup dan mampu memiliki sifat-sifat seperti raja yang selalu bijaksana, adil, dan selalu menjadi teladan bagi anak cucunya.

Acara midodareni adalah acara tirakat di malam sebelum acara ijab kabul dengan permohonan agar ketika acara ijab kabul, mempelai wanita mendapat "titisan" (tertular) kecantikan seperti bidadari. Acara ini berawal dari cerita rakyat Joko Tarub dan Nawang Wulan. Dalam cerita rakyat (folklor), beberapa bidadari turun ke bumi. Namun, ketika mereka mandi di sendang, salah satu pakaian bidadari yang bernama Nawang Wulan dicuri Joko Tarub sehinga Nawang Wulan tidak dapat terbang kembali ke surga. Akhirnya, Nawang Wulan diperistri Joko Tarub sampai memiliki anak dan diberi nama Nawangsih.

Nawang Wulan berpesan kepada Joko Tarub agar jangan sekali-kali membuka dandang (periuk) yang digunakan menanak nasi. Joko Tarub melanggar pesan itu dan akhirnya Nawang Wulan terbebas dari ikatan, kemudian terbang kembali ke surga meninggalkan Joko Tarub dan Nawangsih. Karena itulah, acara midodareni itu mengandung makna pragmatik sebagai permohonan agar para bidadari berkenan hadir kembali ke bumi untuk memberi doa restu agar mempelai wanita dapat cantik secantik bidadari (Andini \& Sefik, 2015). Makna simbolik etnopragmatik adalah bahwa mempelai wanita harus selalu berikhtiar agar mendapat kecantikan seperti bidadari dan sang suami harus selalu menepati janji terhadap apa yang sudah disepakati dengan istri.

Di tengah-tengah midodareni juga diisi dengan acara tantingan, yaitu menanyakan kesanggupan terakhir untuk menikah dengan calon suami. Sementara itu, di malam midodareni mempelai pria melakukan kegiatan jonggolan/nyantri yang dibimbing oleh sesepuh untuk belajar hidup berkeluarga. Makna pragmatik jonggolan adalah acara mengajarkan cara hidup berkeluarga, menyayangi istri dan anak-anak beserta keluarga lain dalam hidup bermasyarakat. Makna etnopragmatiknya adalah bahwa sebagai suami harus selalu taat beribadah sesuai dengan ajaran agama yang dianutnya.

Tahap berikutnya adalah acara inti, yaitu ijab kabul. Tuturan verbal yang diucapkan oleh orang tua atau wali mempelai perempuan adalah sebagai berikut: 
Ayah wanita: Ananda Wahyu Jiwandono bin Bapak Puja Sasmita, saya nikahkan dan saya kawinkan engkau dengan Agnes Yuliati binti Bapak Sastra Rumangsa dengan maskawinnya berupa alat sholat dan uang sebesar Rp 1 juta rupiah dibayar tunai. .

Jawaban mempelai pria: "Saya terima nikah dan kawinnya Erna binti Bapak Djiwandono dengan mas kawin berupa seperangkat alat sholat dan uang tunai sebesar 1 juta dibayar tunai". Pada tahap ini, acara inti sudah selesai.

Makna etnopragmatik ijab kabul adalah acara resmi orang tua perempuan menikahkan mempelai wanita dengan pria calon suami berdasarkan hukum agama dan hukum negara. Dengan acara ijab kabul ini dimaksudkan bahwa kehidupan mereka berdua dilindungi oleh hukum agama maupun hukum negara.

Tahap berikutnya adalah acara panggih. Karena acara ini merupakan acara adat, di setiap daerah ternyata pelaksanaannya berbeda-beda. Ada yang dilaksanakan secara lengkap, tetapi ada yang diambil pokok-pokoknya saja. Beberapa acara yang dilakukan antara lain (a) kepyok (menyentuhkan kembar mayang ke bahu mempelai laki-laki, (b) melempar gantal (saling lempar sirih), (c) wijikan dan injak telur, (d) ikat kain sindur ke pelaminan, (e) sungkeman, (f) kacar-kucur, (g) dhahar kembul (Pringgawidagda, 2010).

Acara panggih diawali dengan kepyok yang dilakukan oleh petugas pembawa kembar mayang ketika mempelai wanita akan dipertemukan dengan mempelai pria. Kembar mayang disentuhkan ke tubuh mempelai pria dengan makna simbolik untuk membuang sial yang ada di tubuh pria. Acara ini berasal dari kisah pewayangan ketika Sri Kresna akan menikahkan Dewi Sembadra dengan Arjuna. Kembar mayang memiliki makna simbolik etnoragmatik bahwa kedua mempelai ketika dipertemukan selalu terhindari dari pengaruh negatif dari apa pun.

Bentuk kembar mayang ada berbagai macam dan semuanya memiliki makna simbolik berupa doa dan harapan, misalnya berbentuk gunung (dengan harapan agar bercita-cita tinggi), keris (agar selalu waspada, bijak dalam menghadapi hidup), pecut "cambuk" (agar selalu optimis dalam menghadapi hidup), payung (agar kedua mempelai selalu menjadi pengayom dan pelindung), dan berbentuk burung (agar selalu termotivasi untuk punya citacita tinggi).

Makna simbolik etnopragmatiknya adalah bahwa kedua mempelai itu diharapkan agar selalu memiliki cita-cita tinggi (setinggi gunung), selalu waspada dalam hidup berkeluarga (pusaka keris), selalu memiliki semangat dan tidak mudah putus asa (cambuk), mampu menjadi pengayom keluarga (payung), selalu termotivasi untuk mewujudkan cita-cita setinggi langit (burung terbang). 
Setelah acara kepyok kembar mayang, acara selanjutnya adalah melempar gantal (sirih yang diisi tembakau, gambir, kapur sirih (semuanya digulung dan diikat dengan benang lawe "benang sutra"). Daun sirih memiliki dua sisi dengan warna yang berbeda, melambangkan bahwa meskipun kedua mempelai semula berbeda tetapi telah terjadi pertemuan sehati antara dua orang pengantin yang berbeda sifat, kepribadian dan jenis kelamin. Makna etnopragmatik melempar gantal dapat dimaknai bahwa meskipun semula memiliki kepribadian yang berbeda, keduanya sudah saling menyatukan hati dalam satu rasa kasih sayang. Dalam sastra Jawa, dalam cerita pewayangan sering dideskripsikan "wis kinocap, lamun sirih beda rupa lumah lan kurepe, nanging yen ginigit pada rasane" (sudah terucap bahwa sirih berbeda warna depan dan belakangnya, namun jika digigit memiliki rasa yang sama).

Acara injak teluar dan wijikan (cuci telapak kaki). Injak teluar adalah simbolisasi bahwa yang memecahkan keperawanan istri adalah suaminya. Di dalam telur ada bibit calon makhluk hidup. Oleh karena itu, suami mengharapkan agar istri setelah menikah segera dikaruniai keturunan dari suaminya. Acara wijikan adalah wujud rasa hormat dan kesetiaan seorang istri kepada suami dalam menjalani kehidupan keluarga. Makna simbolik etnopragmatik pragmatik bahwa keperawanan seorang istri hanya boleh dilakukan oleh suami yang sah dan cuci telapak kaki bahwa seorang istri harus selalu memberikan rasa hormat kepada suami.

Selesai acara injak telur, kedua orang tua membawa mempelai berdua dengan diselimuti kain sindur (batik berwarna merah putih) diarak menuju ke pelaminan. Makna simbolik etnopragmatik adalah untuk mempersatukan kedua mempelai sebagai suami istri yang sah dan diarak menuju ke pelaminan. Di pelaminan kemudian diadakan acara sungkeman. Makna simbolik etnopragmatik sungkeman adalah ucapan terima kasih kedua mempelai kepada orang tua mereka yang sudah merawat dari bayi sampai dewasa. Kedua mempelai sekaligus memohon doa agar kehidupan rumah tangga mereka selalu bahagia.

Acara kacar-kucur mengandung makna simbolik etnopragmatik sebagai pemberian nafkah seorang suami kepada istri. Acara ini ada yang dilaksanakan setelah sungkeman ada pula yang dilaksanakan sebelum sungkeman. Seperti yang telah diuraikan sebelumnya oleh peneliti bahwa variasi pelaksanaan acara adat perkawinan berbeda-beda. Kemudian, diakhiri dengan acara dhahar kembul adalah acara suap-suapan. Hidangan yang disajikan berupa nasi golong (nasi dibentuk bundar) dengan lauk terdiri atas sayuran gudangan, telur dadar, kedelai goreng, rempeyek, kerupuk, tempe goreng, dan ayam goreng. Namun, ada pula yang 
dibentuk tumpeng nasi putih atau kuning. Suami dan istri masing-masing memegang piring yang berisi nasi bersama lauknya, kemudian suami menyuapi istri dan istri menyuapi suami. Acara ini bermakna bahwa kedua pasangan sudah sama-sama sehati. Nasi dibentuk "golong" (bundar) memiliki makna simbolik etnopragmatik bahwa kedua hati telah bundar tekatnya untuk membangun mahligai rumah tangga.

\section{PENUTUP}

Berdasarkan analisis dan pembahasan tersebut, hasil penelitian dapat disimpulkan sebagai berikut. Pertama, wujud acara adat perkawinan gaya Yoyakarta sebagian besar menggunakan bahasa nonverbal. Secara berurutan, acara adat perkawinan Jawa gaya Yogyakarta meliputi urutan (a) nontoni, lamaran, paningsetan, (b) tarup dan bleketepe, (c) siraman, (d) ngerik, (d) midodareni, ( e) jonggolan/nyantri, (f) tantingan, dan (g) majemukan. Tahap inti meliputi (a) ijab kabul, (b) upacara panggih,(c) penyerahan tebusan berupa pisang sanggan, (d) kepyok (menyentuhkan kembar mayang ke bahu mempelai lakilaki, (e) melempar gantal (saling lempar sirih, (f) wijikan dan injak telur, (g) kacar-kucur, (h) sungkeman, dan (i) dhahar kembul. Sebagian besar acara tersebut menggunakan bahasa nonverbal dinamis. Dari urutan acara adat tersebut, hanya ada 3 acara yang menggunakan bahasa nonverbal yang disertai bahasa verbal, yaitu (a) acara paningsetan, (b) acara ijab kabul, dan (c) acara sungkeman.

Kedua, makna simbolik etnopragmatik acara adat perkawinan gaya Yogyakarta diungkapkan dengan menggunakan bahasa nonverbal, baik statis maupun dinamis. Hampir semua acara dan perlengkapan perkawinan diungkapkan menggunakan bahasa nonverbal dinamis yang mengandung makna simbolik etnopagmatik. Kata atau istilah yang mengandung makna simblok etnopragmatik, antara lain (a) lamaran dan paningsetan, (b) pemasangan bleketepe, (c) siraman, (d) ngerik, (d) midodareni, ( e) jonggolan/nyantri, (f) tantingan, (g) majemukan, (h) upacara panggih, (i) kepyok, (j) melempar gantal, (k) wijikan dan injak telur, (1) kacar-kucur, (m) sungkeman, dan (n) dhahar kembul, sedangkan makna simbolik etnopragmatik yang pemaknaannya menggunakan kerata basa, antara lain (a) tebu wulung (antebing kalbu wis gumulung “mantapnya hati sudah bulat”), (b) janur (sakjane ana nur "sebenarnya ada cahaya”), (c) cengkir (kencenging pikir "kuatnya pikiran”), dan (d) tarup (ditata kareben murup "ditata biar gumebyar"). 


\section{DAFTAR PUSTAKA}

Ambarwati \& Anindika, A.P. (2018). Pernikahan Adat Jawa Sebagai Salah Satu Kekuatan Budaya Indonesia. https://doi.org/10.1007/s007790170019

Andini, T. D., \& Sefik, D. (2015). Perancangan Buku Dongeng "Legenda Jaka Tarub" Dengan Software Pengolah Grafis. Jurnal Ilmiah Teknologi Informasi Asia, 9(1), 1-5. https://jurnal.stmikasia.ac.id/index.php/jitika/article/view/91

Brown, G., Yule, G., Brown, G., \& Yule, G. (2013). Introduction: Linguistic Forms And Functions. In Discourse Analysis. https://doi.org/10.1017/CBO9780511805226.003

Cook, G. (2003). Applied Linguistics (Oxford Introduction To Language Study Series). USA: Oxfords.

Dash, N. S. (2008). Context And Contextual Word Meaning. Skse Journal Of Theoretical Linguistic, 21-31. http://www.skase.sk/Volumes/JTL12/pdf doc/2.pdf

Dey, A. K. (2017). Malware Originated Http Traffic Detection Utilizing Cluster Appearance Ratio. International Conference On Information Networking, 248-253. https://doi.org/10.1109/ICOIN.2017.7899513

Hartati, D. (2011). A History Of Cognitive Anthropology. A Companion To Cognitive Anthropology, (July 2011), 9-29. https://doi.org/10.1002/9781444394931.ch1

Hilmi, Hubbi Saufan dan Fabio Testy Ariance Loren. (2019). MedanMakna Aktivitas Tangan dalam Bahasa Sasak Dialek Ngeno-Ngene, Ranah: Jurnal Kajian Bahasa, 8 (1), 53-75. https://doi.org/10.26499/rnh.v8i1.625

$\mathrm{Hu}$, X. (2014). Context: From Static To Dynamic. 2(2), 127-133. https://doi.org/10.11648/J.Ij11.20140202.21

Hua, T. K., Farah, N., \& Nayef, M. (2012). Communication Strategies Among Efl Students - An Examination of Frequency of Use and Types of Strategies Used. Gema Online Journal of Language Studies, 12(3), 831-848. http://ejournal.ukm.my/gema/article/view/1058

Koentjaraningrat. (2000). Kebudayaan, Mentalitas Dan Pembangunan. Retrieved From https://books.google.com/books?Id=94qpz-X117qc\&Pgis=1

Lapakko. (2016). Using Nonverbal Communication In Efl Classes Aysenil. (January).

Nuning, Z. (2016). Performativitas Panggih Pada Upacara Perkawinan Adat Jawa Tengah Prespektif Performance Studies. Imajinasi Jurnal Seni, X(1). https://doi.org/10.15294/imajinasi.v10i1.8818

Pratama, B. A. (2018). Pernikahan Adat Jawa di Desa Nengahan, Kecamatan Bayat, Kabupaten Klaten. Haluan Sastra Budaya, 2(1), 19-40. https://doi.org/10.20961/hsb.v2i1.19604

Pringgawidagda, S. (2006). Tata Upacara dan Wicara: Pengantin Gaya Yogyakarta. Yogyakarta: Kanisius.

Sari, P. (2017). Nilai-Nilai Religius yang Terkandung dalam Tradisi Perkawinan Adat Jawa ( Studi Kasus Desa Cerme Kecamatan Pace Kabupaten Nganjuk ). Litera, 01(07), 67=81.

Setyaningsih E. (2015). Adat Budaya Siraman Pengantin Jawa Syarat Makna dan Filosofi. Teknobuga, 2(2), 19=39. https://journal.unnes.ac.id/nju/index.php/teknobuga/article/view/6427

Singgih, D. S. (2017). Prosedur Analisis Stratifikasi Sosial dalam Perspektif Sosiologi. Jurnal Masyarakay, Kebudayaan dan Politik, Vol. 20(1) 1-10. http://journal.unair.ac.id/MKP@ prosedur-analisis-stratifikasi-sosial-dalam-perspektifsosiologi-article-2074-media-15-category-8.html

Studi, P., Bahasa, P., \& Mada, U. G. (2016). Konsep Diri dalam Budaya Jawa. Buletin Psikologi, 20(1-2), 26-35. https://doi.org/10.22146/bpsi.11946

Suwardi. (1996). Prinsip "Othak-Athik Mathuk" dalam Penafsiran Falsafah Aksara Jawa. Cakrawala Pendidikan, Xv(2). Cakrawala, Xv(2), 37-44. https://doi.org/10.21831/cp.v2i2.9229

Takkaç Tulgar, A. (2019). A Tal of Two Contexts: Attitudes Of Learners Towards Listening In Foreign Context and Target Context. International Journal of Listening. https://doi.org/10.1080/10904018.2019.1604139

Tannenbaum, N. (2017). Review Reviewed Work ( $S$ ): Participant Observation By James P . Spradley Review By: Nicola Tannenbaum Published By: The George Washington University Institute for Ethnographic Research Stable Url: http://www.jstor.org/stable/3318111. 
(March), 4-7. https://doi.org/10.2307/3318111

Verschueren, J. (2008). Context and Structure In A Theory of Pragmatics. Studies in Pragmatics 10, (1983), 14-24. https://doi.org/10.3765/bls.v20i1.1456

Widdowson, H. G. (1989). Knowledge of Language and Ability for Use. Applied Linguistics 10. https://doi.org/10.1093/applin/10.2.128

Yuwati, H. (2018). Makna Simbolis yang Terdapat pada Riasan Wajah dan Aksesoris pada Pengantin Gaya Yogya Paes Ageng. Socia Akademika, 4. 